\section{MCQs and learning}

\author{
By Joe Bouch
}

Joe Bouch

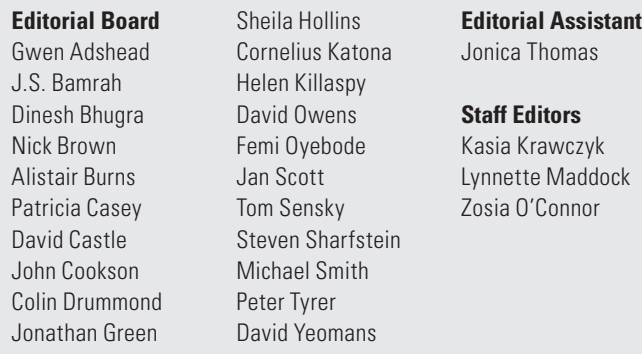

\section{Subscriptions}

Advances Volume 16, 2010 (six issues)

(full airmail f19/US\$34 extra)

Members of the
Royal College
of Psychiatrists Non-members Institutions

\begin{tabular}{lccc}
\hline Print (+free online) & & & \\
Europe (\& UK) & $£ 62$ & $£ 130$ & $£ 141$ \\
USA & US\$110 & US\$205 & US\$243 \\
Elsewhere & $£ 69$ & $£ 140$ & $£ 152$
\end{tabular}

Online (only)

Worldwide

£39/US\$63 £103/US\$155 £128/US\$199

Payment may be made by cheque/money order, by Access/Master Card/ Visa/American Express, or by UNESCO coupons. EC subscribers: please supply your Member State Code and Value Added Tax (VAT) number.

Payment should be made to Maney Publishing, Suite 1C, Joseph's Well, Hanover Walk, Leeds LS3 1AB, UK (tel: +44 (0)113 243 2800; fax: +44 (0)113 386 8178; email: subscriptions@maney.co.uk). For subscriptions in North America, please contact Maney Publishing North America, 875 Massachusetts Avenue, 7th Floor, Cambridge, MA 02139, USA (tel: 866 2975154 (toll-free); fax: 617354 6875; email: maney@maneyusa.com).

Continuing professional development (CPD) Those wishing to register for CPD with the Royal College of Psychiatrists should contact the CPD unit (tel: +44 (0)20 72352351 , ext. 108 or 112). There is no charge for participation in the CPD scheme for Members, Fellows and Affiliates of the College.

CPD Online The College also publishes an interactive online learning facility for CPD in psychiatry. Further details, sample modules and subscription information can be viewed at www.psychiatrycpd.co.uk. Discounts are available for Advances subscribers.

Correspondence Letters submitted for publication should be emailed to Dr Joe Bouch at apt@rcpsych.ac.uk or posted to Advances in Psychiatric Treatment, Royal College of Psychiatrists, 17 Belgrave Square, London SW1X 8PG.

Printed by Henry Ling Ltd, 23 High East Street, Dorchester, Dorset DT1 $1 \mathrm{HD}$.

(C) The Royal College of Psychiatrists 2010. Published by the Royal College of Psychiatrists, a charity registered in England and Wales (228636) and in Scotland (SC038369). Unless so stated, material in Advances in Psychiatric Treatment does not necessarily reflect the views of the Editor or the Royal College of Psychiatrists. The publishers are not responsible for any errors of omission or fact.

The College crest is a registered trade mark of the Royal College of Psychiatrists.

ISSN 1355-5146
Readers may have noticed new text on the inside front cover of Advances. Psychiatrists participating in the American Medical Association (AMA) CME system can now claim credits by completing the MCQs that feature at the end of each article. Although MCQs are not universally loved, the attractions of using them for summative assessment are significant. Wellwritten MCQs are reliable, test breadth of knowledge and are easy to administer and mark. Certificates generated through the College's CPD Online website (www.psychiatrycpd.co.uk) give evidence of participation in CPD and CME programmes. Such evidence, held in portfolios, is kept for regulatory processes such as appraisal and revalidation.

MCQs can also be used for personal development. In the first issue of Advances the Editor wrote: 'There will be opportunities for the reader to test what has been learnt from each article in the form of a few multiple choice questions' (Sims 1994). This in a nutshell is formative assessment - a personal test of understanding rather than a formal evaluation of knowledge. Answering MCQs gives feedback in self-assessment, checking for yourself rather than proving to someone else. Not knowing the best answer reveals a gap in knowledge. Getting a question wrong may be more useful still. 'It is impossible for a man to learn what he thinks he already knows', observed the Greek Stoic philosopher Epictetus (c. 55-135AD). The disquiet experienced in finding out you are wrong when sure you are right, cognitive dissonance, is at the root of all learning. It has been called 'learning-by-disturbing' (Robinson 2003). And testing supports not only learning but also remembering. We sense that repeatedly reading an article is a good strategy to aid recall. But we are deceived. Testing has a powerful positive effect on long-term retention which re-reading does not (Roediger 2006). What follows is that, to be helpful for learning, MCQs ought to focus on the key points of an article. Trivial, ambiguous or superficial questions (and answers) are unhelpful. Authors should use questions to signal their take-home messages.

\section{Developmental dyslexia}

Thambirajah (pp. 299-307) points out that, although dyslexia is 'bound to be overrepresented' in the clinics of CAMHS practitioners, 'its relationship, if any, to adult mental health is very limited'. Nevertheless, his article, which is my Editor's Pick, will be of interest to many non-specialists. The author teases out the precise deficits and discusses whether dyslexia is a categorical disorder or simply at the extreme end of a spectrum of reading ability. The impact on the child may be substantial, and thus an important aspect of psychiatric intervention is 'facilitating navigation through their normal developmental tasks'. He touches on language, culture, biology and history in an educational article which is intellectually stimulating without being patronising.

\footnotetext{
Sims A (1994) Introducing continuing professional development. Advances in Psychiatric Treatment 1: 3-8.
}

Robinson P, Purves I, Wilson R (2003) Learning support for the consultation: information support and decision support should be placed in an educational framework. Medical Education 37: 429-33.

Roediger HL, Karpicke JD (2006) Test-enhanced learning: taking memory tests improves long-term retention. Psychological Science 17: 249-55. 